Fletcher and P.F. Narten (1952), Geol. Survey Circular Nr. 225, Washington. -18. Haberlandt, H. (1952), Fortschr. d. Mineralogie 31, 76. - 19. Haas, H. (1953), Radex Rundschau, H. 7/8, 459. Vergl. auch: Meixner, H., Ebenda, 468. - 20. Noll, W. (1949), Heidelberger Beitr. z. Mineralogie, 1, 593. - 21. Bотоvik, S. A., and J.D. Gotman (1939), Bull. Acad. Sci. USSR, Math.-naturw. Ser. 23 Nr. 4, 351. 22. Leutwein, F. (1951), Freiberger Forschungshefte. Nr. 8, 8. - 23. Rost, F. (1939), Z. f. angew. Min. 2 H. 1, 1. Vergl. dazu auch Hegemann, Fr. (1943), Z. fo angew. Min. 4, 121. - 24. Hegemann, Fr. (1948), Fortschr. d. Mineralogie 27, 45, 25. Haberlandt, H. (1949), Sitz.-Ber. Akad, d. Wiss. Wien, Math.-naturw. KI. Abt. I. 158, 609. Vergl. dazu auch: Sitz-Ber. Akad. d. Wiss. Wien, II a, 144, 135. Derselbe, B. Karlik, und K. Przibram (1935). - 26. Schneiderhöhn, H. (1952), N. Jb. f. Min. Monatshefte 2/3, 47. Derselbe (1953), N. Jb. f. Min. Monatshefte 9/10, 223. Vergl, dazu auch: Leitmeier, $H$. (1953), Kober-Festschrift. Wien, 228, - 27. Haberlandi, $H$., und A. Schiener (1951), Tscherm. Min. u. petr. Mitt. III. Folge, 2, 257.28. Haberlandt, H. (1941), Chem. d. Erde, 14, 107. - 29. Matveyeff, C. (1932), N. Jb. f. Min. Beil.-Bd. 65, 233. - 30. Murata, K. J., H.J. Rose and M.K. Carron (1953), Geochim. Cosmochim. Act. Vol. 4, 292. - 31. Leitmeier, H. (1949), Tscherm. Min. u. Petr. Mitt, 3/1, 390, - 32. Königsberger, J. (1942), Schweizer Mineral. u. Petr. Milt.22, 85. - 33. Clar, E. (1945), Verh. d. Geolog. Bund. Anst. Wien, 29. Derselbe (1953), 42, 107. - 34. Ahrens, L. H. (1945), Trans. of the Geol. Soc. of S. Africa Vol. 48 207. Ferner unter zahlreichen anderen einschlägigen Arbeiten (1950), Americ. Mineralog. 35, 571. - 35. Oftedal, 1. (1943), Norsk. geologisk. tidsskr. Oslo, 23, 202. - 36. Nockolds, S. R., and R.L. Mitchell (1948), Trans. Royal Soc. 61, 535. - 37. Wager, L.R., and R. L. Mitchell (1951), Geochim. et Cosmochim. Acta 1, 129. - 38. Wedepohl, K. H. (1953), Geochim. et Cosmochim. Acta. Vol. 3, 93. - 39. Becke, F. (1912), Denkschriften d. Akad. d. Wissensch. Wien, Math.-naturw. Kl. - 40. Angel, F, und R. Staber (1937), Tseherm. Min. u. petr. Mitt, 49. - 41. Exner, Chr. (1953), Radex Rundschau, Radenthein, H. 7/8, 41\% - 42. Köhler, A. (1951), Erdöl-Zeifung, Nr. 5, ä6. - 43. Rankama, K. (1946), Bull. Com. Géol. Finl. (Helsinki) No. 137. 44. Goldschmidt, V.M. (1921), Vidensk. Selskapet. Skrift. Math.-naturw. KI. Kristiania (Oslo), Nr. 10. - 45. Higazy, R. A. (1952), Geochim. et Cosmochim. Acta, Vol. 2, 170. - 46. Landergren, St. (1948), Serv. Geol. Undersökn. Stockholm, Ser. C, No. 496.

\title{
Anmerkung bei der Korrektur
}

Zu Anmerkung 1 (S. 110): In letzter Zeit wurde der Ausdruck "Mikroparagenese" von H.Meixner (Referat Zentralbl. II (1953), 2/3, 262) einer ablehnenden Kritik unterzogen. Er meint, daß man den Ausdruck ,Mikroparagenese“ nur in der Bedeutung Mikromineralparagenese im Hinblick auf den Begriff Mineralparagenese verwenden sollte. Demgegenüber ist festzustellen, daß der Ausdruck ,Mikroparagenese" als übergeordneter Begriff gelten soll, der sowohl die Spurenelemente, die von EinschluBmineralen herruhren, als auch die Spurenelemente, die als kristallchemisehe Bausteine des Wirtsgitters aufzufassen sind, beinhaltet. Man könnte höchstens ergänzend schreiben: "Mikro-Elementparagenese".

Zur Literatur: Ad.6. Von Herrn Prof. F. Hegemann (München) wurde uns mitgeteilt, daß von ihm und $F$. Albrecht eine umfangreiche Arbeit: „Zur Geochemie oxydischer Eisenerz" mit über 800 Analysen von Spurenelementen in der Zeitschrift Chemie der. Erde, Jena, im Druck ist. In dieser Arbeit wird hauptsächlich die Bedeutung der Streubereiche (Konzentrationsbereiche) von Spurenelement-Gehalten in Magnetiten verschiedener Lagerstätten hervorgehoben. - Ad. 13. Vergl. auch $\mathrm{Ku}$ tina, J. (1950). Bull. Int. Acad. Tschech. Scienc. 20. Ferner: Morinagu, K. (1952), Bull. Nagoya Inst. Technol. 4228 (Japan). - Ad 26. Vergl. auch: Andreatta, C., (1953), N.Jb. f. Min. Mh. 5/6, 131. Ferner: Petraschek, W. E. (1952), Berg- u. Hüttenm. Mh. $9 \%, 108$. 